\title{
Research on Wuhan's Advanced Manufacturing Development Policy
}

\author{
Dong Liang ${ }^{1}$ and Zhongwei Zhang ${ }^{2 *}$ \\ ${ }^{1}$ Jianghan University Business School, Wuhan \\ ${ }^{2}$ Jianghan University Business School, Wuhan \\ 1925243770@qq.com²1039857158@qq.com \\ * The Corresponding author
}

Keywords: Advanced manufacturing; Development; Wuhan; Policy Support

\begin{abstract}
In recent years, the manufacturing industry has been continuously developing towards automation and intelligence. The advanced manufacturing industry as a typical representative of the manufacturing industry is a highly integrated product of mechatronics. At present, advanced manufacturing has become the most important and most dynamic component of manufacturing, representing the development direction of the world's manufacturing industry. The development of advanced manufacturing industry is an important part of a country's economic competitiveness, a key area for participating in international competition and highlighting national competitive advantages, and also an important carrier for innovative applications and breakthroughs in innovation. Based on the analysis of China's advanced manufacturing government support policy, this paper analyzes Wuhan's advanced manufacturing support policy based on the current status of Wuhan's advanced manufacturing industry, and proposes suggestions for improving Wuhan's advanced manufacturing development policy.

Perface: Since entering the 21st century, the manufacturing industry has faced the opportunities and challenges brought about by the adjustment of global industrial structure. In particular, after experiencing the financial crisis in 2008 , countries began to face the pressure of transformation and upgrading of the manufacturing industry. In order to find new ways to promote economic growth, all countries have begun to pay attention to the development of advanced manufacturing. In 2011, the United States proposed the "Advanced Manufacturing Partner Program" to increase investment in technological innovation. Germany followed up with the implementation of the Industry 4.0 strategy in 2013, and China has established clear advantages in the international market after the reform and opening up with the rapid development of manufacturing. However, the traditional mode of extensive manufacturing has gradually lost its advantages. Using advanced technology as a means of production is an inevitable trend in the future development of the manufacturing industry. Faced with this situation, China's manufacturing industry must rise to catch up, and it must not give up its advantages in the traditional manufacturing industry, but it must actively compete for the commanding heights of advanced manufacturing.
\end{abstract}

\section{Analysis of Government Support Policies for Advanced Manufacturing Industry in China.}

All countries have paid great attention to the role of government support. Through the formulation of a series of policy measures, we will actively promote the development, demonstration, and application of key technologies in advanced manufacturing industries and strategic emerging industries, and create a favorable market environment for promoting the development of advanced manufacturing industries, smart manufacturing technologies, and strategic emerging industries.

The Development Status of China's Advanced Manufacturing Industry.

As China's economy has entered the "new normal," a variety of social problems have begun to escalate, such as high prices, rapid price increases, and severe link pollution. The Chinese government has taken active measures to promote the transformation and upgrading of the manufacturing industry in the face of the problems in the manufacturing industry. "Made in China 2025" is a strategic plan made by the Chinese government in a comprehensive analysis of the current situation of the development of advanced manufacturing at home and abroad. As China's 
existing resources are difficult to support the development of traditional manufacturing, traditional manufacturing is in urgent need of transformation. The rising production costs of the labor force, raw materials, etc., have reduced the competitive advantage of manufacturing products, causing some developed countries to relocate their advanced manufacturing industries to cheaper Southeast Asian countries for production.

With the support of national policies in recent years, China's advanced manufacturing industry has improved. However, compared with the world advanced level, China's manufacturing industry is still large and not strong. There is a clear gap between independent innovation capability, resource utilization efficiency, industrial structure level, informationization level, and quality and efficiency. The task of transformation, upgrading, and striding over development is urgent and arduous. In recent years, developed countries such as the United States and Germany have increasingly focused on the development of advanced manufacturing industries and have successively introduced the bill to revitalize the development of advanced manufacturing industries. Against this background, the Chinese government is also actively transforming itself from a "manufacturer" to a "manufacturer" and achieve leapfrog development in advanced manufacturing.

\section{Analysis of China's Advanced Manufacturing Support Policies.}

In response to the arrival of the third industrial revolution. The government of our country combines China's national conditions and focuses on key areas such as innovation-driven, intelligent transformation, strengthening of the foundation, green development, and talent-based, as well as advanced manufacturing, high-end equipment and other key areas. It has proposed major strategic tasks and major policy initiatives to accelerate the transformation and upgrading of the manufacturing industry, increase efficiency, and strive to enter the ranks of manufacturing powerhouses by 2025. "Made in China 2025" is an effort and attempt to promote the transformation of China from a manufacturing powerhouse to a manufacturing powerhouse. In the document, the Chinese government put forward the basic policy of "innovation-driven, quality-first, green development, structural optimization, and talent-based", and proposed to improve the national manufacturing innovation capability, promote the deep integration of information technology and industrialization, and strengthen the industrial foundation. Capacity, strengthening of quality brand building, full implementation of nine key tasks such as green manufacturing, and breakthrough development in key areas.

To make the "Made in China 2025" plan achieve the expected results, some key issues need to be solved, including the implementation of innovation-driven development strategy, the construction of new economic infrastructure, the allocation of resources to the real economy, the dynamic adjustment of key technologies and domain catalogues, and the promotion of "craftsmen spirit" strengthens the cultivation of skilled talents and draws on international experience to bring China into the "first square" of manufacturing and truly become a manufacturing powerhouse. "Made in China 2025" is based on the trend of international industrial change and has made a major strategic plan to comprehensively upgrade the quality and level of China's manufacturing industry. It is of great significance to promote the adjustment and reform of China's industrial structure, accelerate the development of China's advanced manufacturing industry, increase the international competitiveness of China's manufacturing industry, and make China a manufacturing powerhouse.

\section{Development Trend of China's Advanced Manufacturing Industry.}

With the impact of economic globalization, the development of advanced manufacturing is developing toward the trend and direction of intelligence, high-end, lean, and green. With the continuous adjustment and upgrading of the advanced manufacturing industry structure, the market size of China's smart manufacturing equipment continues to expand in recent years. Smart manufacturing is one of the innovative trends in advanced manufacturing. Developed countries such as Europe and the United States have emphasized the importance of smart manufacturing in their advanced manufacturing development plans and have formulated detailed technological innovation plans and incentives. Therefore, intelligentization and high-endization are inevitable directions for the development of advanced manufacturing industries in the future. For example, cloud manufacturing, smart manufacturing, and the Internet of Things are products of advanced 
manufacturing intelligence.

The advanced manufacturing industry continuously optimizes and upgrades the products that are manufactured to be both precise and highly productive, and able to respond to changing user needs. And can make the redundant part of the production process be streamlined, and ultimately achieve the best results in all aspects of production including market supply and marketing. Traditional manufacturing is produced at the expense of the environment. The advanced manufacturing industry emphasizes the recycling of clean production and resources. Taking into account the natural environment and social efficiency, the products provided are characterized by no pollution, low energy consumption, and recyclability. Through the green revolution of the entire industrial production process from the design, manufacture, marketing, and circulation processing of manufacturing industries, the sustainable development of the manufacturing industry is realized.

\section{Analysis of Support Policies for Wuhan's Advanced Manufacturing Industry Development.}

In recent years, Wuhan's advanced manufacturing industry has developed rapidly and has now become the main support for the city's economic growth and the most dynamic new growth point. Among them, the optoelectronic information product manufacturing industry and the software industry have developed particularly rapidly and have become increasingly important in the city's advanced manufacturing industry. However, its development still faces unfavorable factors such as unreasonable industrial structure, relatively weak corporate brand economic strength, and weak corporate independent innovation capability. How to analyze and identify problems in a timely manner, so that Wuhan's advanced manufacturing industry to a higher level is the most important development.

\section{The Status Quo of Wuhan's Advanced Manufacturing Industry Development.}

With the rapid development of Wuhan's economy, Wuhan has now initially achieved a transformation from an old industrial base to an advanced manufacturing base with industrial clustering characteristics. More than 80 of the world's top 500 companies have invested in Wuhan. The East Lake New Technology Development Zone in Wuhan has been approved by the National Independent Innovation Demonstration Zone to form a high-tech industrial cluster represented by optoelectronic information. The industrial concentration of the advanced manufacturing industry has significantly increased in the past two years. In the high-end equipment manufacturing industry, Wuhan Jinyun Laser Co., Ltd. was established as one of the first batch of 21 demonstration companies for cultural and technological integration in Wuhan. The company is dedicated to the digital application of laser and 3D printing. The "Gold Laser 3D Digital Technology Application Service Innovation Platform" was constructed, extending the application industry chain and providing a comprehensive, innovative and leading digital solution for the downstream applications of laser and 3D printing.

Wuhan currently has a number of emerging industries such as lasers, robots, new energy, rail transit, and new materials. However, as a whole, at present, no significant core competitiveness has yet been formed. Existing industries are still in the process of cultivation and growth, and their R\&D capabilities and ability to grasp the market are relatively weak. Whether they can grow into leading companies in the industry and build well-known brands in the industry will require further market inspections. Compared with other cities, the existence of problems such as irrational industrial structure, lack of brand features, and poor ability to independently innovate seriously restricts the industrialization and large-scale development of Wuhan's advanced manufacturing industry.In addition, with the continuous development of China's advanced manufacturing industry, there has been a fundamental change in the situation where scientific research results are not valued, and society's thirst for transforming scientific research achievements into productivity has become increasingly strong. However, in the process of industrialization, the contradiction between demand for and supply of scientific and technological achievements is very prominent. The projects with high technological level, good market prospects, and independent intellectual property rights are very difficult to find, and a large number of venture capitals are idle due to lack of good projects. The lack of continuous innovation in technology and the lack of technological stamina have become 
major issues affecting the sustainable development of Wuhan's advanced manufacturing industry.

\section{Analysis of Supportive Policies for the Development of Advanced Manufacturing Industry in Wuhan.}

In August 2005, General Secretary Hu Jintao emphasized the need to speed up Hubei's development and become an important strategic fulcrum for the rise of the central region. During the National "Two Conferences" in 2009, Premier Wen pointed out that Wuhan is the central city and the most important central city. In the implementation of the strategy for the rise of central China, the state requested Wuhan to inherit the east and west of Kaixi to play a fulcrum, and to take the lead in the rise of industrial development and economic development and build an important national energy raw material base, modern equipment manufacturing and high-tech industrial base.With the support of the strategy for the rise of Central China, Wuhan's manufacturing industry will enter a period of rapid development. At present, the world has entered an unprecedented era of innovation and industry revitalization, strategic emerging industries will become the dominant force in economic and social development. Donghu New Technology Development Zone has been approved to build a national demonstration zone for independent innovation, which will bring opportunities for innovative development ideas and institutional mechanisms for Wuhan. Giving full play to the advantages of intensive science and technology resources and active technological innovation in East Lake High-tech Development Zone and enhancing the competitiveness of independent innovation in the city will lead to a rapid transformation of the development mode of Wuhan's manufacturing industry.

Robotics industry has become the Main Direction. With the rapid development of advanced manufacturing technology in the pace of industrialization, advanced manufacturing has become an important part of Wuhan's high-tech industry. As an important part of advanced manufacturing technology, Wuhan robots have received increasing attention in recent years. Hubei Province formulated the "Opinions on Accelerating the Development of Six Key Industries such as Equipment Manufacturing" and "Accelerating Action Plan for the Development of Equipment Manufacturing Industry in the Province". It is clear that the competitiveness of high-end equipment manufacturing industries such as industrial robots and additive manufacturing (3D printing) must be improved. This year, the Economic and Information Technology Commission issued the "Accelerating Action Plan for Accelerating the Province's Smart Manufacturing Equipment Industry Development", which clearly put forward the action path, action priorities, action goals, and safeguard measures for the development of the industrial robot industry.

In accordance with the requirements of the provincial government, Wuhan actively promoted the development of the robot industry and did a lot of useful work. The Wuhan municipal government has always insisted on the development of the robot industry as an important starting point for Wuhan's innovative development strategy. As a pioneer in speeding up the industrial transformation and upgrading of Wuhan and the scale development of "Wuhan Zhizhao", it is an accelerator for the construction of a comprehensive innovation and reform pilot zone, a national innovation city, and a state-level manufacturing innovation center. Since the beginning of this year, the "Opinions of the Wuhan Municipal People's Government of Wuhan Municipality on Accelerating the Promotion of All-round Innovation in Building a National Innovative City," and "Wuhan Manufacturing 2025" have been intensively introduced, as well as the intensified integration plan of Wuhan's informatization and industrialization. The thirteenth five-year plan for the development of the equipment manufacturing industry has included industrial robots and smart manufacturing as development priorities and main targets.

Advanced Manufacturing Enterprises Become the Focus of Government Support. China has officially promulgated the "CPC Central Committee's Proposal for Formulating the 13th Five-Year Plan for National Economic and Social Development" and the "Made in China 2025" overall plan. In the industries that the country mainly supports the development of robotics, advanced rail transit, aerospace equipment, and bio-pharmaceuticals, Wuhan has laid a relatively solid industrial foundation and has certain advantages in advance. As a national-level center city, Wuhan City attaches great importance to the development and construction of advanced 
manufacturing industries. The "March 2025 Wuhan Outline for Action on Manufacturing Industry" promulgated in February 2016 clearly stated that it will strive to build the city into a national advanced manufacturing center by 2025. It will provide strong support for the coordinated development of the city's economy and society, and will play a demonstration role for China's entry into the world's manufacturing powerhouse.

Wuhan will comprehensively deepen reforms and make every effort to create an industrial innovation system. Actively promote various tasks such as smart parks, enterprise clouds, big data, and public production platforms, and strive to meet the new equipment needs of various industrial sectors, the new consumer demands of the people, and new capacity requirements for social governance services. It will certainly provide a vast space for development and impetus for Wuhan's advanced manufacturing industry.

Limited support for high-tech industry policy. In recent years, Wuhan has achieved rapid development in high-tech industries, especially the development of optoelectronic information product manufacturing and software industries. However, compared with Shanghai and Beijing, which have developed rapidly, Wuhan has a relatively weak foundation to engage in advanced manufacturing. Wuhan's key innovation resources such as scientific research institutions and colleges and universities are relatively weak. Wuhan's policy support for advanced manufacturing industries is also relatively inadequate. The number of business parks attracting high-level overseas students, key universities, and scientific research institutions is relatively small, and the grade is low. Due to Wuhan's special geographical location, the direction of policy tilt is concentrated in modern finance, high-end real estate and other industries. In the future, the gap between Wuhan City and the advanced urban areas in the field of high-tech industries may further widen. The most important fund for the development of high-tech industries comes from venture capital. However, as Wuhan's position in the regional financial market is far less than that of Shanghai and Shenzhen, the risk funds that can be provided are not only of small scale but also of unreasonable structure. The financial shortage has severely restricted the industrialization and large-scale development of high-tech industries in Wuhan.

In addition, the legal service system is not perfect and the response is not timely, which also seriously restricts the growth of high-tech industries in Wuhan. As the pace of urbanization and the pace of transformation have accelerated, the resources of industrial land available for use have become increasingly scarce, and the cluster advantage of large-scale advanced manufacturing in Wuhan has ceased to exist. With the continuous advancement of the strategy of building a national-level center city in Wuhan, the functions of Wuhan's core business districts and government districts have become increasingly prominent, promoting the rapid development of the tertiary industry, and the proportion of advanced manufacturing industries in total economic output of the region will continue to decline. We must strengthen overall planning and forward-looking deployment, and resolutely target the relevant industries supported by the state, and unswervingly advance the development of advanced manufacturing industries. Take full advantage of the new generation of information technology, accelerate the transformation of enterprises' digitization, networking and intelligence, and promote the transformation of traditional industries from manufacturing to manufacturing and service. To shape the regional characteristics of Wuhan's advanced manufacturing industry, forge a batch of companies with international competitiveness, and seize the commanding heights of advanced manufacturing.

\section{Wuhan's Advanced Manufacturing Government Support Policy Recommendations.}

The huge potential of China's advanced manufacturing market provides a broad market space for the development of advanced manufacturing. However, compared with advanced manufacturing areas, Wuhan's advanced manufacturing technology research and development and market expansion are still not balanced. In addition, the low numerical control rate of technical equipment in industries related to advanced manufacturing cannot meet the market demand for medium and high-end advanced products. Looking at the competition and development of the international manufacturing industry, we are faced with the gradual integration of the two advanced 
manufacturing markets at home and abroad. How to integrate the decentralized corporate resources according to the market demand of Wuhan's advanced manufacturing industry and form its own technological superiority in the advanced manufacturing industry as soon as possible is an urgent issue facing Wuhan's advanced manufacturing industry.

To enhance the independent innovation capability of advanced manufacturing enterprises in Wuhan.

Advanced manufacturing is an important carrier of scientific and technological innovation, an area where innovation is most concentrated and most active, and a fertile ground for innovation to be applied and applied. The Wuhan Municipal Government should focus on promoting the leap-forward development of advanced manufacturing enterprises in policies and guide the forward-looking vision of advanced manufacturing enterprises in targeting the development of advanced manufacturing industries at home and abroad. Selectively introduce and digest, absorb, and innovate advanced manufacturing technologies with high $\mathrm{R} \& \mathrm{D}$ costs, long research and development cycles, and significant benefits of import. Promote high-level grafting of advanced manufacturing technologies, give full play to their advantages in post-production, and realize leap-forward progress in low-cost, short-term, and high-efficiency.

Adhere to a high starting point to advance the innovative leap-forward development of Wuhan's advanced manufacturing enterprises, relying on China's existing advanced manufacturing technology foundation, and accelerate the research and development of advanced manufacturing technology. We will give all-round and key support to advanced manufacturing companies with independent innovation awareness and independent intellectual property rights to improve the core competitiveness of Wuhan's advanced manufacturing enterprises. We will earnestly construct an enterprise-led industrial technology research and development system, and strive to promote the collaborative innovation of various innovative entities such as industry, universities, and research institutes and improve the original innovation capabilities of enterprises. Finally, we must promote the application and industrialization of results with core independent intellectual property rights, nurture and develop strategic emerging industries, and upgrade the overall level of innovation of Wuhan's advanced manufacturing enterprises.

\section{To vigorously nurture the talents needed for the development of advanced manufacturing in Wuhan.}

The development of Wuhan's advanced manufacturing industry is inseparable from talents. In addition to supporting policies in terms of personnel training, exchange, and introduction, the government should actively establish various talent platforms. Such as talent exchange platform and introduction platform, talent training platform, especially the cultivation platform for innovative talents, use these platforms to carry out talent introduction and training. Specifically, a special fund for talents can be set up and a green channel for talents can be set up. It can be used exclusively for talent introduction, training, commendation, motivation and key talent projects. In the high-end talent section, key talents are supported and special talents are specially trained. In the professional talents section, we will implement a plan for updating the expertise of talented professionals and focus on key areas. We will carry out large-scale continuous education of knowledge renewal, and cultivate urgently needed and backbone professional and technical personnel. In the grass-roots talent section, the "blue-collar" high-skilled personnel forging plan will be implemented to cultivate the skills needed for the transformation and upgrading of the industry.

Actively introduce domestic advanced technology innovation teams and form deep cooperation with university research institutes. Strengthen the advanced manufacturing talents to go back to college for further education or retraining, actively promote the implementation of the "Innovative Talents Promotion Plan" in the advanced manufacturing field, and strengthen the introduction and training of talented people in areas such as strategic emerging industries. We will strengthen cooperation among universities, enterprises, and scientific research institutes in China to foster a group of young and talented young and middle-aged scientific and technological talents, management talents, and senior technicians. In particular, we must cultivate leading personnel for major equipment development and system design. Actively build a talent flow platform and green 
channels both inside and outside the country and at home and abroad, establish an information system for overseas students and senior talents in developed regions, establish an overseas talent pool based on the development of Wuhan's robotics industry, and attract talents back to Wuhan to start businesses.

\section{Strengthen support for key areas and accelerate the conversion of results.}

"Made in China 2025" in the context of the specific conditions of our country, has identified the ten major areas of advanced manufacturing manufacturing. To achieve sustainable technological innovation and transformation of achievements in the key areas of advanced manufacturing is the focus that our government should focus on. To promote technological breakthroughs in key areas, we must formulate policies and measures to guide the development of the industry in light of China's specific national conditions and concentrate on solving key problems. Guide the development of advanced manufacturing to the high end and original direction of the value chain, avoiding disordered competition and low-end redundant construction. In addition, for key areas, it is necessary to strengthen government financial support and promote continuous innovation in the advanced manufacturing industry.

At this stage, the cycle of transformation of scientific research results is getting shorter and shorter. If a scientific research result does not translate into productivity within the conversion cycle, its economic potential will quickly decline. The U.S. Advanced Manufacturing Research Center has integrated scientific research institutions, companies, and government resources, and has achieved seamless integration of research, development and application, and has promoted the industrialization of innovative results. At present, the conversion rate of scientific research in China is obviously low, only about $10 \%$, lower than the average level of $40 \%$ in developed countries, and even lower than the level of $80 \%$ in the United States. In promoting the integration of production, education and research, "Made in China 2025" also made a useful attempt. A group of manufacturing innovation centers will be formed around the major common needs of the transformation and upgrading of key industries and the development of new-generation information technology and other fields, focusing on industrial fundamentals and common key technologies for $R \& D$ and achievement industrialization. If you want to further research and solve the problems of science and technology in economic and industrial development, the government needs to build a modern industrial system, cultivate a series of strategic emerging industries, and develop modern service industries. This will promote the transfer and transformation of scientific and technological achievements and promote the leap in the high-end and value-added industries and products.

\section{Promote the development of advanced manufacturing clusters.}

Industrial clusters refer to the grouping of a group of interconnected companies, suppliers, associated industries, and specialized systems and associations within a specific area. Through this kind of regional agglomeration to form an effective market competition, we have constructed a set of specialized production factors to optimize agglomeration. Enable enterprises to share regional public facilities, market environment and external economy, reduce information exchange and logistics costs, and form regional agglomeration, scale, external and regional competitiveness. In close connection with the market orientation, government departments should give full play to their guiding role and guide the rational distribution of various industries with the industrial cluster development plan. Give full play to the guiding role of the government, attract advanced manufacturing companies at home and abroad to settle in, increase financial support for basic supporting facilities and advanced demonstration areas in industrial clusters, and take advantage of new financial financing platforms to promote the development of China's advanced manufacturing enterprises and gradually expand.

Promote the spatial concentration of advanced manufacturing enterprises in China. Combining with the promotion of urbanization, and in accordance with the functional requirements and comparative advantages of various regions, we will break administrative divisions, make overall planning and layout, optimize resource allocation, guide industrial agglomeration, and advance the rationalization of China's advanced manufacturing layout. Focusing on cultivating and supporting a group of leading enterprises to enable them to quickly scale up and create brands, and become the 
core of the development of advanced manufacturing clusters, thus enhancing the overall competitiveness of China's advanced manufacturing industry. It is necessary to strengthen planning and guidance, taking leading enterprises as the main body, relying on industrial agglomeration areas, and in accordance with the requirements of rational industrial division of labor, targetedly introduce large enterprises and develop core industrial clusters. Increase the degree of industrial agglomeration and promptly create a large group of companies to drive the further development of related companies.

\section{Conclusion}

With the continuous development of the manufacturing industry, advanced manufacturing industry has also been increasingly mentioned. While Wuhan's advanced manufacturing industry has a wide range of application prospects and huge market potential, it also ushered in unprecedented competitive pressures and challenges. . In recent years, although China has made great progress in its research on advanced manufacturing, it has made breakthroughs in key technologies, but it still lacks breakthroughs in the overall core technology. Although applications have spread across all walks of life, they are still large but not strong. Policy support centered on technological innovation, personnel training and enhanced competitiveness can fundamentally solve the impetus and vitality of advanced manufacturing. Therefore, our government should strengthen the support for Wuhan's advanced manufacturing industry, and promote the development of Wuhan's advanced manufacturing industry through policy support. Wuhan should combine its own characteristics to form its own distinctive development.

\section{Acknowledgement}

Manufacturing Industry Development Research Center on Wuhan City Circle, Jianghan University

\section{References}

[1] Hong Jiang Yujie Du, Yihe Liu. Research on the Development Policy of Advanced Manufacturing at China and Abroad [J]. New Materials Industry, 2016(05):44-46.

[2] Feng Li. Research on innovation policy in the United States based on policy elements[D]. University of Electronic Science and Technology, 2016.

[3] Yang Pan, Ruyi Luo. The Enlightenment of Advanced Manufacturing Development Policies in Developed Countries to Hangzhou[J].Hangzhou Science and Technology,2014(05):56-60.

[4] Peng Lei. Research on Wuhan advanced manufacturing technology capacity improvement path [D]. Wuhan Textile University, 2013.

[5] Tao Zhang. Research on Manufacturing Industry Development Strategy in Wuhan[D]. Wuhan University of Technology, 2009.

[6] Jianfeng Chen. Analysis on the Restrictive Factors of Wuhan's Construction of Advanced Manufacturing Center in Central China[J]. Journal of Pingdingshan University, 2008(02):29-36.

\section{The authors introduce}

Dong Liang ${ }^{1}$ : 1960 - a professor at Jianghan University Business School, is mainly engaged in the research of enterprise strategy and government strategy.

Zhongwei zhang':1994-Jianghan University Graduate School of Business, the main research direction for marketing and service engineering. 